\title{
Water and energy savings from greywater reuse: a modelling scheme using disaggregated consumption data
}

\author{
J. Knutsson ${ }^{1}$ (D) P. Knutsson ${ }^{2}$ D
}

Received: 3 September 2020 / Accepted: 18 October 2020 / Published online: 7 November 2020

(c) The Author(s) 2020

\begin{abstract}
Municipal drinking water supplies are under great stress globally, and one way to mitigate the problems is the reutilization of wastewater in various settings. In this paper, a greywater reuse scheme and the impact of system design and configuration on water and energy savings are investigated. The objective of the paper was to investigate the impact of hydraulic design and performance of a greywater treatment and reuse system on water and energy savings. A simulation model was created based on real, disaggregated water consumption data that predicts the reuse potential. Three scenarios were investigated; (1) greywater collection from the bathroom and reuse for toilet flushing, (2) greywater collection from bathroom sinks and showers, and reuse as hot water for sinks and showers, and (3) a combination of (1) and (2) where greywater collection from bathroom sinks and showers is used for toilet flushing, sinks and shower. The results indicate hot water reductions between 55.6 and $58.2 \%$, while cold water reductions ranged from 5.8 to $30.6 \%$. Reductions in energy for producing hot water between 43.5 and $46.8 \%$ were observed. Recommendations per connected user for hydraulic design ranged from 0.033 to $0.1 \mathrm{dm}^{3} \mathrm{~min}^{-1}$, $3 \mathrm{dm}^{3}$, and $0.7-10 \mathrm{dm}^{3}$ for treatment capacity, collection and holding tank volume.
\end{abstract}

Keywords Greywater $\cdot$ Comprehensive data $\cdot$ Reuse $\cdot$ Simulation

\section{Introduction}

It is estimated that in 2019 two billion people were living in countries affected by some degree of water stress and that up to four billion people are living in conditions where they face water scarcity at least one month per year (Boretti and Rosa 2019; WWAP 2019; Wada et al. 2016; Mekonnen and Hoekstra 2016). Decades of efforts being made in decreasing domestic water consumption have resulted in stagnant or even decreasing per capita use of water (Bradley 2004). Still, the combination of trends in urbanization, population growth and changing climate patterns threaten to put further pressure on regional and local freshwater resources. This increasing pressure is reflected in multiple policy formulations such as the European union regulation on minimum requirements for water reuse (European 2018). To take some

$\triangle$ J. Knutsson

jesper.knutsson@chalmers.se

1 Architecture and Civil Engineering, Chalmers University of Technology, Göteborg, Sweden

2 Chemistry and Chemical Engineering, Chalmers University of Technology, Göteborg, Sweden pressure off already stressed water supplies and municipal distribution systems, various wastewater reuse schemes have been proposed and to some extent implemented in many countries and regions (Al-Jayyousi 2003; Zhang et al. 2009; Mandal et al. 2011; Oron et al. 2014).

Among the existing reuse schemes, decentralized approaches, including rainwater harvesting (RWH), greywater recycling (GWR) and hybrid rainwater-greywater systems (HRG) have been the ones most often described in the literature. A Monte-Carlo simulation was performed to obtain data on the domestic greywater (shower/bath, wash basin and washing machine) reuse together with rainwater reuse to supply toilet flushing. In their study they found that reusing the rainwater and the domestic water single tanks storage of $50 \mathrm{~L}$ were sufficient to cover up to $80 \%$ of the needed toilet flushing supply (Dixon et al. 1999). In a different study in Brazil an attempt was made to collect water usage data by distributing total water consumption to individual uses/appliances based on interview data. The results from the study pointed on potential saving of 28.7-34.8\% potable water for greywater reuse alone, and $39.2-42.7 \%$ when combined with rainwater harvesting (Ghisi and Ferreira 2007), where potential water savings were calculated 
for greywater reuse and rainwater harvesting for toilet flushing separately and in combination.

A study covering both greywater, rainwater and hybrid reuse systems used metered monthly total consumption and statistical average consumption together with literature data on detailed end-usage to derive per appliance consumption. In this study, $95.3,92.1 \%$, and $100 \%$ non-potable mains water savings (toilet flushing and irrigation) were reported for RWH, GWR and HRG systems respectively (Leong et al. 2019).

The majority of the published papers investigating the saving potentials from water reutilization system design, to the knowledge of the authors, use water consumption data that is either derived from standard water use patterns and Monte Carlo simulations (Dixon et al. 1999; Villarreal and Dixon 2005), or short term monitoring in a small number of households which is subsequently extrapolated to the desired size (Butler 1991; Alberto Campisano and Modica 2014; Alberto Campisano and Modica 2010). Even though this approach produce results that can demonstrate the potential of greywater and rainwater reuse for future water and energy savings, it still does not provide the fidelity in output that is needed in order for the existing designs to be applied and for the technology to be further optimized. There is also scarcity of papers differentiating between reuse scenarios and modelling their outcomes. This paper aims to fill this gap in the scientific literature.

The specific objective of this work is to investigate the impact of hydraulic design and performance of a greywater treatment and reuse system on water and energy savings in different reuse configurations. Data were collected from September to November 2019 in Gothenburg, Sweden. To achieve the objectives three scenarios for greywater recycling are examined; (1) water collection from bathroom sinks and reuse as cold water for toilet flushing, (2) water collection from bathroom sinks and showers and reuse as sink/ shower hot water and (3) water collection from bathroom sinks and showers hot water and reuse as sink/shower hot water and cold water for toilet flushing. To calculate water and energy saving potential of the three scenarios as well as the impact of additional parameters that can influence the water use, such as e.g. tank volume, treatment capacity and reuse prioritization when there are water limitations, model simulations are performed using long-term, disaggregated water usage data and by applying an iterative simulation code. The examination of treatment processes, economic considerations and water quality, which of course are crucial in any greywater reuse scenario scenarios are not treated in the present study and will be subjects for future work.

\section{Materials and methods}

The model created for this paper was based on a greywater reuse system that was installed in a living lab in Gothenburg, Sweden (HSB Living Lab, HLL). The living lab building comprises 29 apartments and studio apartments with permanent occupancy, occupied by 32 people who live permanently in the building. Like most apartment buildings in Sweden HLL a centralized hot water system was installed, where municipal drinking water is heated to approximately $60{ }^{\circ} \mathrm{C}$. The building is equipped with sensors for monitoring, among other parameters, disaggregated water consumption, providing data on individual micro consumption points of the users, as has been described in detail elsewhere (Knutsson and Marx 2016).

The data used for the model comprises water consumption data collected from ZigBee-enabled rotary vane water meters (Lund Science AB, Sweden) installed on individual micro use points. Data from water meters were collected (resolution $1 \mathrm{~L}$ and 10-min interval reporting) and stored in a database. Currently, 3 years of disaggregated water use data has been collected. For the purpose of this paper 2 months of data was utilized. The data structure that was used in the model is shown in Table 1.

The greywater treatment and reuse system presently installed in the HLL that was simulated in this work, was at the time of writing connected to only six bathrooms, collecting greywater from bathroom sink and shower, while resupplying the treated water back to two bathrooms in a pilot system setup. This setup constitutes an on-site wastewater differential treatment system (OWDTS), as it requires
Table 1 An example of data used for the simulation showing the structure of the model input

\begin{tabular}{lllllll}
\hline Timestamp & ID & Value & Type & Room_type & Room_number & Attached_to \\
\hline 2019-09-24 00:06 & 270881 & 0.002 & Hot water & Studio apartment & 2208 & Kitchen \\
2019-09-24 00:02 & 270880 & 0.005 & Cold water & WC common & 2215 & Toilet \\
2019-09-24 00:01 & 270879 & 0.001 & Cold water & Studio apartment & 2208 & Sink \\
2019-09-24 00:14 & 270882 & 0.009 & Cold water & WC & 3102 & Toilet \\
2019-09-24 00:15 & 270883 & 0.005 & Cold water & WC & 3107 & Toilet \\
2019-09-24 00:20 & 270886 & 0.005 & Cold water & Studio apartment & 2106 & Kitchen \\
\hline
\end{tabular}

The column named "ID" contain a unique identifier for that particular data point, the "value" column contains the consumption data 
source separation of black water (toilet), higher-load grey water (kitchen, washing machines) and lower-load greywater (shower, basin) (Zavala, et al. 2002).

Based on the collected data and for the purpose of the created model, within the present study it was assumed that the treatment system was connected to collect and reuse water from all 35 apartment bathrooms. Thus, it was not feasible to directly validate the model using the current installation and this will be the subject of future work.

A simulation code was created for this work using PHP programming language. The code is publicly available in a Github repository under standard MIT license (Knutsson 2019). For the purpose of the simulation code the treatment process was conceptualized as a straightforward mass balance system as shown in Fig. 1.

Input, treatment and output are calculated stepwise based on current collection and reuse scheme and the underlying consumption data. The simulation was iterated in 10-min epochs, with 3-4 input parameter and 3-6 level variations. The input parameters used in the simulation model are explained in Table 2.

The rationale for the reuse threshold is that it from an energy preservation point of view is sub-optimal to reuse already heated water for toilet flushing and should only be allowed if there is a "surplus" of reclaimed and treated water in the system. This parameter is relevant and applied only

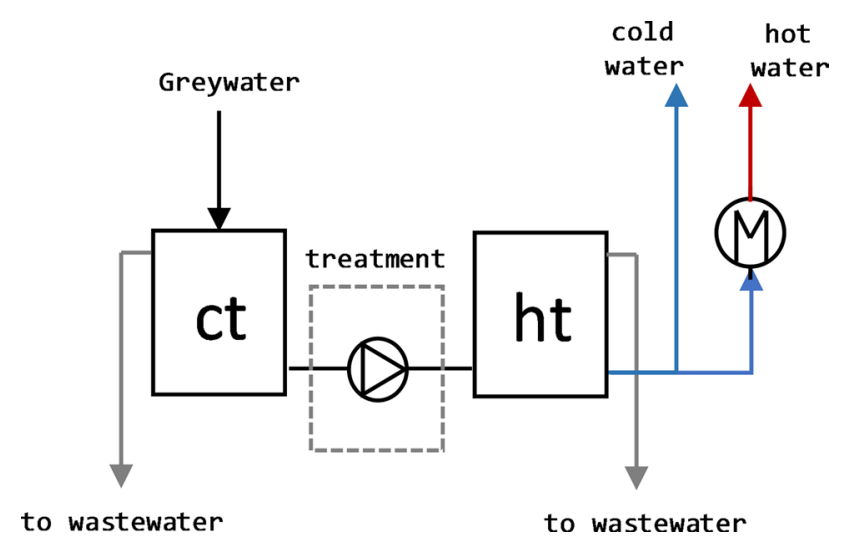

Fig. 1 Schematic drawing of the treatment process modelled in the simulation used in this paper. Key: $c t$ collection tank, $h t$ holding tank in one of the scenarios in this work (scenario 3). The basic logical structure of the model code is shown in Fig. 2.

The simulation yielded both disaggregated and aggregated output data, where a description of the output parameters can be found in Table 3 .

Three scenarios, as described schematically in Fig. 3, were simulated in this work. In scenario 1 it was assumed that only greywater from the bathroom sinks was collected and reused for toilet flushing. In scenario 2, which coincides with the current installation scenario in the living lab, grey water is collected from bathroom sinks and showers, and after treatment recycled as hot water for sink and shower reuse. Scenario 3 is identical with scenario 2, with the addition of toilet flushing reuse (Table 4).

Within the present treatment modelling simulation the mass balance for the collection tank is described by

$\mathrm{CT}=\mathrm{GW}-\mathrm{Of}_{\mathrm{CT}}-\mathrm{TW}$.

The mass balance for the holding tank is described by

$\mathrm{HT}=\mathrm{TW}-\mathrm{Re}_{\mathrm{HW}}-\mathrm{Re}_{\mathrm{CW}}-\mathrm{Of}_{\mathrm{HT}}$,

where, CT is the collection tank, GW is the greywater collected during the time interval, $\mathrm{Of}_{\mathrm{CT}} / \mathrm{Of}_{\mathrm{HT}}$ is the overflow from collection tank and holding tank respectively, TW is the treated water, i.e. water processed in the water treatment system, $\mathrm{HT}$ is the Holding tank, $\mathrm{Re}_{\mathrm{HW}}, \mathrm{Re}_{\mathrm{CW}}$ is the treated water that is reused as hot (HW) and cold water (CW) respectively.

Water savings were based on the recycled and the baseline water volume and calculated according to the following equation

Water savings $\%=\frac{V_{\text {recycled }}}{V_{\text {baseline }}} \times 100$,

where $V_{\text {recycled }}$ is the simulated volume of recycled water in $\mathrm{m}^{3}$, and $V_{\text {baseline }}$ is the measured baseline consumption in $\mathrm{m}^{3}$.

When recycled hot water is returned to the user at a lower feed temperature (nominally $42{ }^{\circ} \mathrm{C}$ ), the demand for cold water mix-in (to lower the point-of-use temperature of the hot water to a comfortable level) will be reduced. To reflect this, simulation uses a standard $80 \%$ reduction ratio that is applied to cold water demand when recycled hot water is

Table 2 Explanation of simulation model parameters used for the treatment modelling simulation

\begin{tabular}{ll}
\hline Model input parameter & Explanation \\
\hline Collection tank volume $\left(\mathrm{m}^{3}\right)$ & Defines the volume of the collection tank which contains the untreated greywater \\
Holding tank volume $\left(\mathrm{m}^{3}\right)$ & Defines the volume of the holding tank which stores the treated greywater until reuse \\
Reuse threshold $(\%)$ & $\begin{array}{l}\text { Defines the fill rate of the holding tank, below which treated water will be restricted } \\
\text { to use only as hot water }\end{array}$ \\
Treatment capacity $\left(\mathrm{m}^{3} \mathrm{~min}^{-1}\right)$ & Defines the volume capacity per minute of the treatment system
\end{tabular}




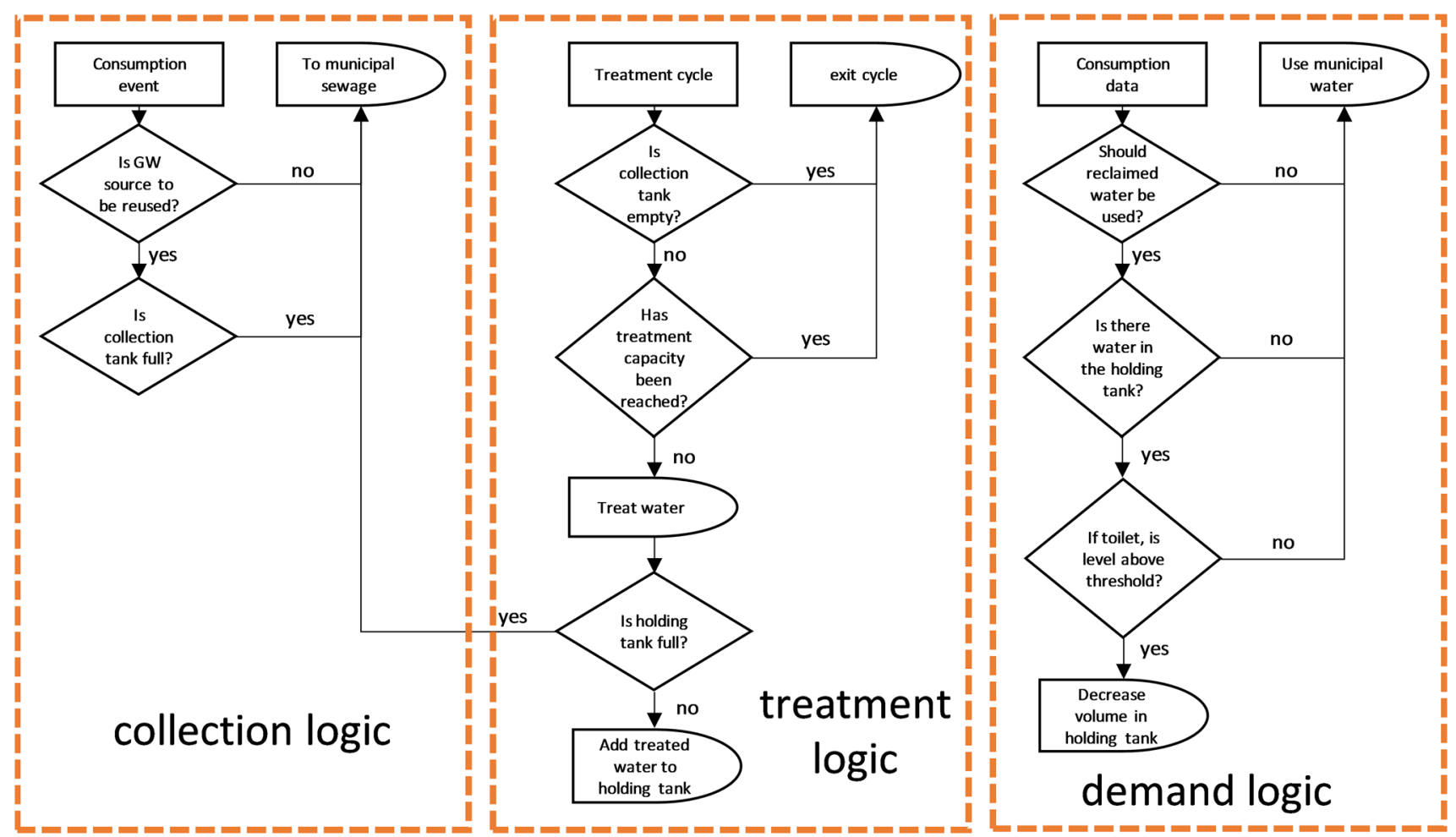

Fig. 2 A schematic description of the model code logic for collection, treatment and demand handling

used, while the recycled hot water demand is increased by the same amount.

To calculate energy expenditure of the recycling schemes an experiment of energy consumption was conducted for treatment and recycling of $0.6 \mathrm{~m}^{3}$ of shower water in using the existing installation in HLL described above. The results of this experiment were used for the modelling and is presented in Table 5

The standard energy needed to supply one cubic meter of hot water in Sweden is $55 \mathrm{kWh}$, based on average increase of temperature from cold to hot water. The standard energy expenditure (saving) for recycled hot water under these conditions was calculated to $-34.3 \mathrm{kWh} \mathrm{m}^{-3}$.

While the use of a standard value represents a simplification it still allows the comparison of energy expenditure between scenarios. Reusing treated water as cold-water results in a net loss of energy compared with using municipal drinking water $\left(1.66 \mathrm{kWh} \mathrm{m}^{-3}\right)$. However, it is worth noting that the calorific gain from filling toilet reservoirs with temperate water instead of cold water was not included in this analysis.

The fidelity of the model needs to be improved on three points; to include dynamic calculation of energy demand for
Table 3 Description of the simulation output parameters obtained by the treatment modelling simulation

\begin{tabular}{lll}
\hline Output parameter & Unit & Description \\
\hline Hot water reuse & $\mathrm{m}^{3}$ & The volume of treated greywater reused as hot water \\
Cold-water reuse & $\mathrm{m}^{3}$ & The volume of treated greywater reused as cold water \\
Collection tank overflow & $\mathrm{m}^{3}$ & The volume of overflow in the collection tank \\
Hot water reduction & $\%$ & \\
Cold-water reduction & $\%$ & \\
Wastewater reduction & $\%$ & Sum of reused hot and cold water \\
Hot water deficiency & $\mathrm{m}^{3}$ & Occurs when there is demand but no availability for recycled hot water \\
Cold-water deficiency & $\mathrm{m}^{3}$ & Occurs when there is demand but no availability for recycled cold water \\
Energy consumption rela- & $\mathrm{kWh}$ & - \\
tive baseline & & \\
\hline
\end{tabular}


A

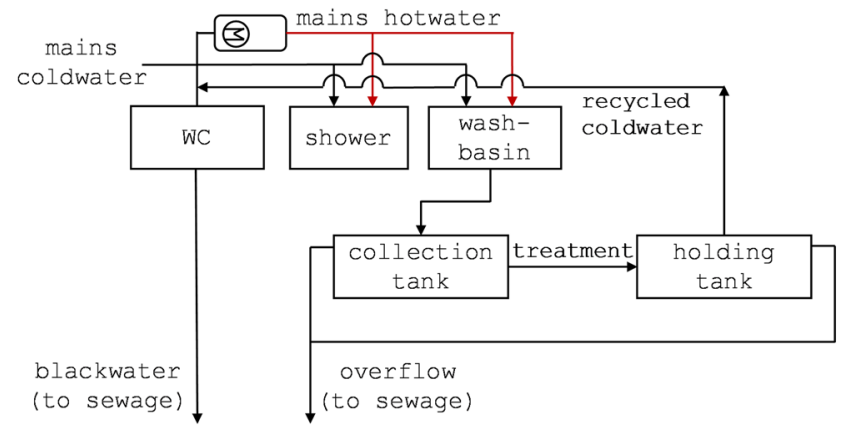

\section{B}

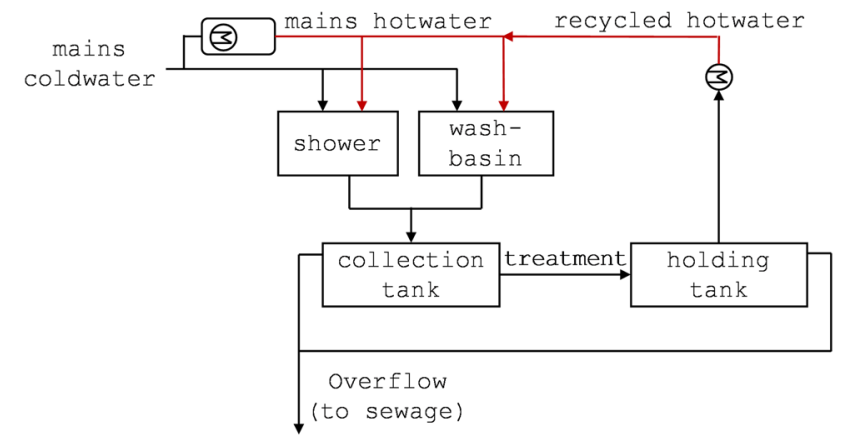

C

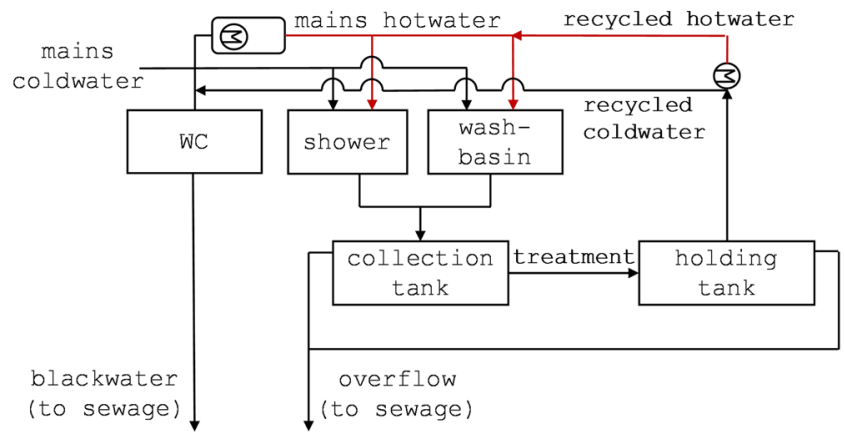

Fig. 3 Schematic descriptions of the three scenarios for the greywater treatment and reuse system which are modelled in this paper

Table 4 Parametric level input to the simulation per simulation scenario used for the treatment modelling simulation

\begin{tabular}{llll}
\hline & Scenario 1 & Scenario 2 & Scenario 3 \\
\hline Collection tank volume $\left(\mathrm{m}^{3}\right)$ & $0.02-0.1$ & $0.05-0.30$ & $0.05-0.30$ \\
Holding tank volume $\left(\mathrm{m}^{3}\right)$ & $0.02-0.1$ & $0.05-0.30$ & $0.05-0.30$ \\
Treatment capacity $\left(\mathrm{m}^{3} \mathrm{~min}^{-1}\right)$ & $0.001-0.006$ & $0.001-0.005$ & $0.002-0.010$ \\
Toilet flushing reuse threshold & - & - & $0-0.8$ \\
$\begin{array}{l}\text { Number of factor levels per parameter } \\
\text { and number of simulations }(n)\end{array}$ & $5 \times 5 \times 6=150$ & $6 \times 6 \times 5=180$ & $3 \times 3 \times 5 \times 5=225$ \\
\hline
\end{tabular}

Table 5 Results for measurements of energy consumption of the components in the greywater reuse system

\begin{tabular}{lllll}
\hline & $\begin{array}{l}\text { Treatment } \\
\text { process }(\mathrm{kWh} \\
\left.\mathrm{m}^{-3}\right)\end{array}$ & $\begin{array}{l}\text { Heating } \\
(\mathrm{kWh} \\
\left.\mathrm{m}^{-3}\right)\end{array}$ & $\begin{array}{l}\text { Pumps to } \\
\text { pressurize } \\
\text { water circuit } \\
\left(\mathrm{kWh} \mathrm{m}^{-3}\right)\end{array}$ & $\begin{array}{l}\text { Total }(\mathrm{kWh} \\
\left.\mathrm{m}^{-3}\right)\end{array}$ \\
\hline Cold water & 0.66 & - & 1.0 & 1.66 \\
Hot water & 0.66 & 15.9 & 1.0 & 17.56 \\
\hline
\end{tabular}

heating to produce hot water, based on municipal drinking water temperature instead of using standard value. A dynamic calculation of reduction of cold-water consumption due to

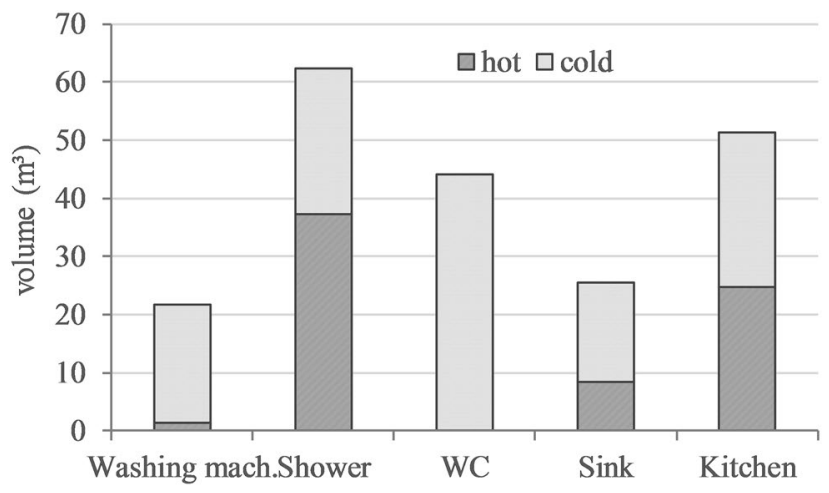

Fig. 4 Baseline consumption of hot and cold water per micro-use point for the data time period described in the present work 
Table 6 Summary of the data obtained in the simulation output for the three scenarios described in this work

\begin{tabular}{|c|c|c|c|c|c|c|}
\hline & \multicolumn{2}{|c|}{$\begin{array}{l}\text { Scenario } 1 \text { (number of } \\
\text { simulations } n=150 \text { ) }\end{array}$} & \multicolumn{2}{|c|}{ Scenario $2(n=180)$} & \multicolumn{2}{|c|}{ Scenario $3(n=225)$} \\
\hline & Average & SD & Average & SD & Average & SD \\
\hline Hot water reuse $\left(\mathrm{m}^{3}\right)$ & - & - & 49.50 & 5.67 & 47.29 & 5.28 \\
\hline Cold-water reuse $\left(\mathrm{m}^{3}\right)$ & 22.20 & 0.51 & - & - & 33.34 & 5.79 \\
\hline Collection tank overflow $\left(\mathrm{m}^{3}\right)$ & 0.72 & 0.51 & 35.39 & 5.74 & 4.50 & 4.28 \\
\hline Hot water reduction (\%) & $0.0 \%$ & $0.0 \%$ & $58.2 \%$ & $6.6 \%$ & $55.6 \%$ & $6.1 \%$ \\
\hline Cold-water reduction (\%) & $16.7 \%$ & $0.4 \%$ & $5.8 \%$ & $0.7 \%$ & $30.6 \%$ & $3.9 \%$ \\
\hline Wastewater reduction (\%) & $10.8 \%$ & $0.2 \%$ & $24.4 \%$ & $2.8 \%$ & $39.4 \%$ & $2.1 \%$ \\
\hline Hot water deficiency $\left(\mathrm{m}^{3}\right)$ & - & - & 3.56 & 4.29 & 5.38 & 4.09 \\
\hline Cold-water deficiency $\left(\mathrm{m}^{3}\right)$ & 15.69 & 0.67 & 0.00 & 0.00 & 7.31 & 3.79 \\
\hline $\begin{array}{l}\text { Energy consumption relative } \\
\text { baseline }(\mathrm{kWh})\end{array}$ & 36.9 & 0.9 & -1853.1 & 212.1 & -1715.2 & 204.5 \\
\hline
\end{tabular}
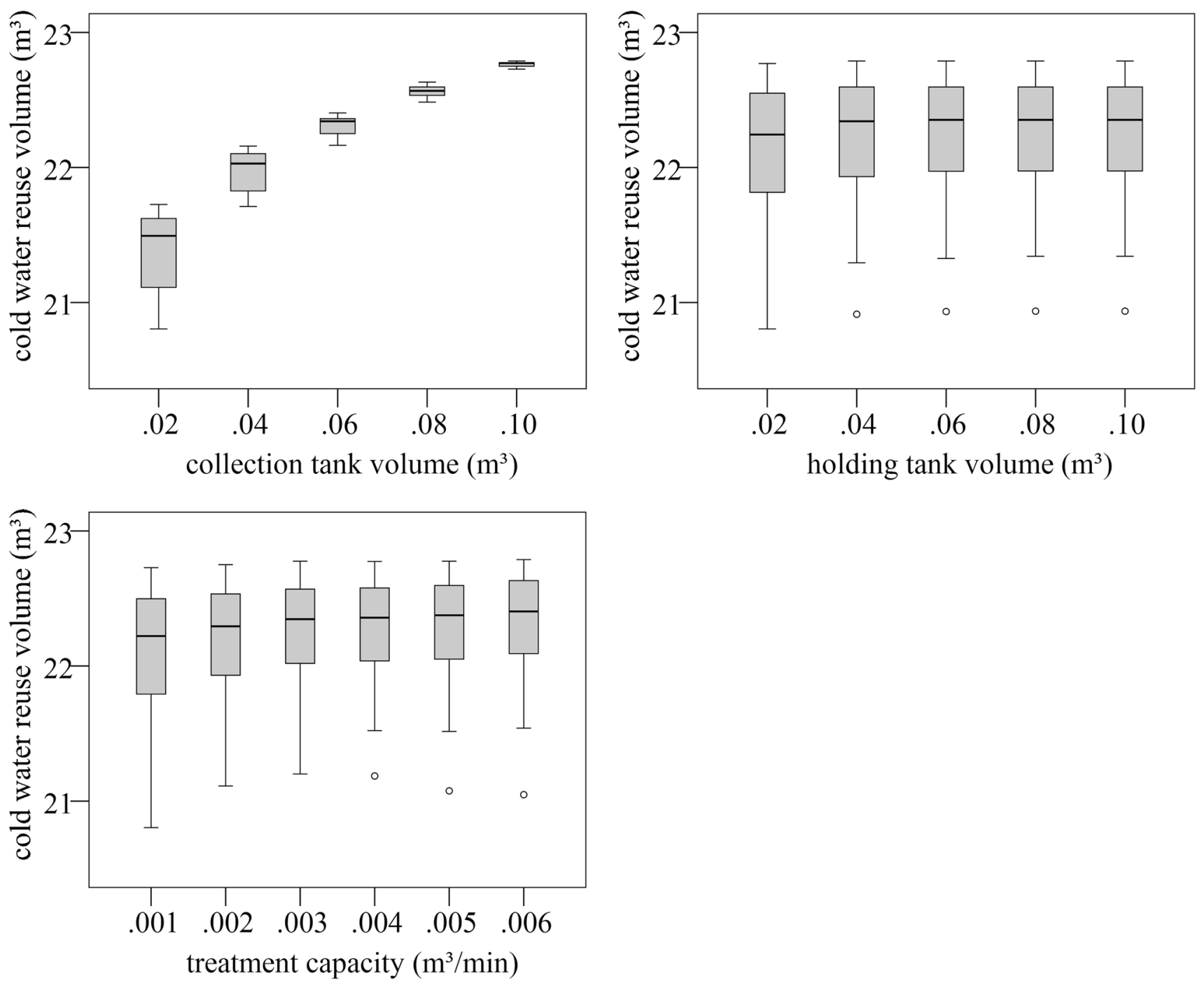

Fig. 5 Box-plots of the simulation output for sink collection and toilet flushing recycling, for collection tank volume (upper left), holding tank volume (upper right) and treatment capcity (lower left) 
Table 7 Summary of the Anova analysis of the factor impact on simulation output variation for recycled cold water volume

\begin{tabular}{lrrlrl}
\hline & \multicolumn{1}{c}{ SS } & \multicolumn{1}{c}{$d f$} & MS & \multicolumn{1}{l}{$F$} & $p$ value \\
\hline A (collection tank volume) & 35.98 & 4 & 8.99 & 7752.43 & $1.07 \times 10^{-102}$ \\
B (holding tank volume) & 0.51 & 4 & 0.13 & 109.84 & $1.12 \times 10^{-31}$ \\
C (treatment capacity) & 1.10 & 5 & $2.19 \times 10^{-1}$ & 188.93 & $8.89 \times 10^{-43}$ \\
A $\times$ B & 0.44 & 16 & $2.77 \times 10^{-2}$ & 23.91 & $5.65 \times 10^{-24}$ \\
A $\times$ C & 0.82 & 20 & $4.12 \times 10^{-2}$ & 35.48 & $1.36 \times 10^{-31}$ \\
B $\times$ C & 0.11 & 20 & $5.35 \times 10^{-3}$ & 4.61 & $4.40 \times 10^{-7}$ \\
Within & 0.09 & 80 & $1.16 \times 10^{-3}$ & & \\
Total & 39.05 & 149 & 0.262 & & \\
\end{tabular}

utilization of lower temperature recycled hot water, and the subsequent increase in hot water consumption. Lastly, the inclusion of calorific balance due to transporting and storing water with various temperatures in the building would add
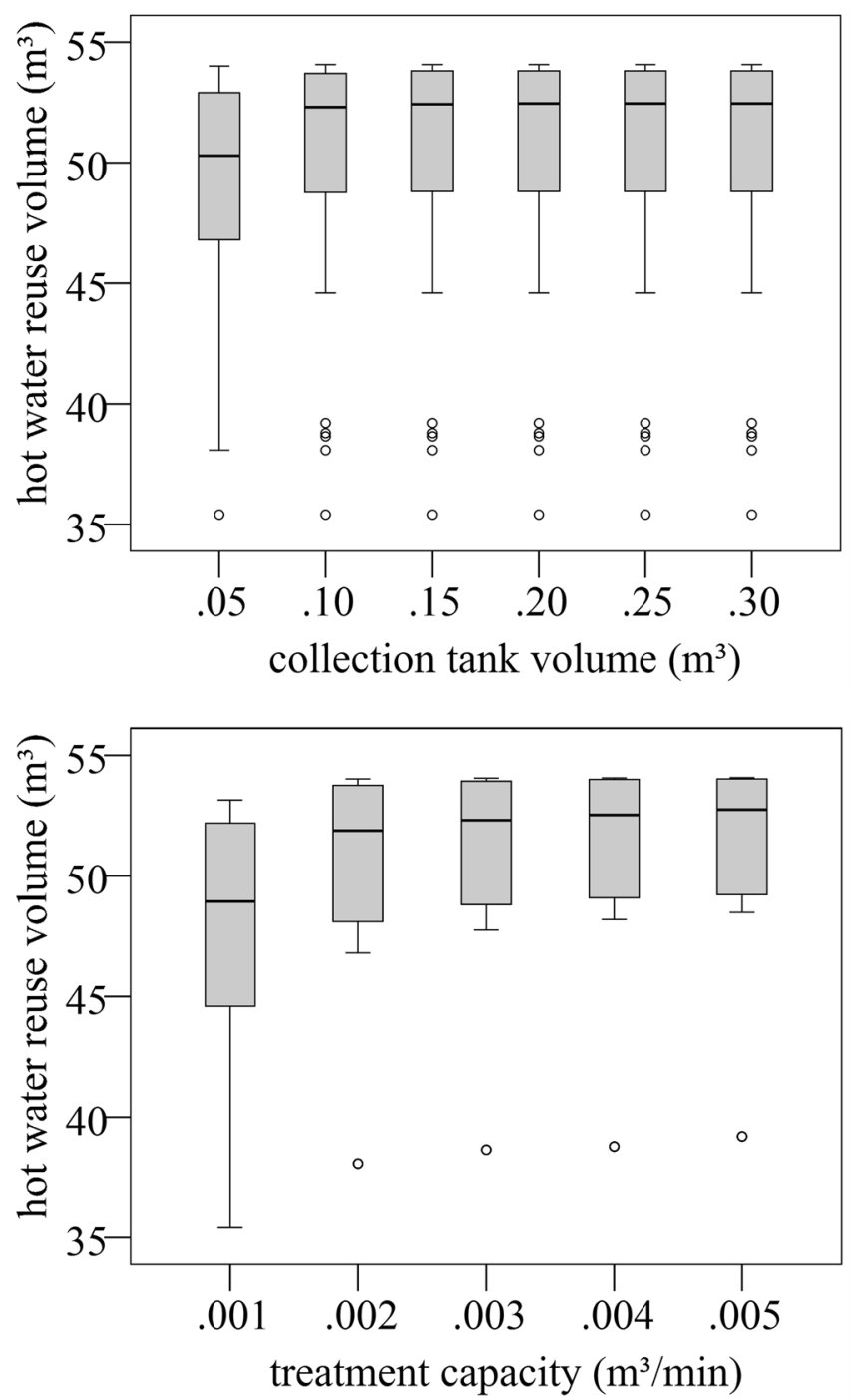

further confidence to the model. All of these improvements are intended to be incorporated in a future version of the model.

Model output data were analyzed and evaluated using ANOVA. We acknowledge that the datasets violate the

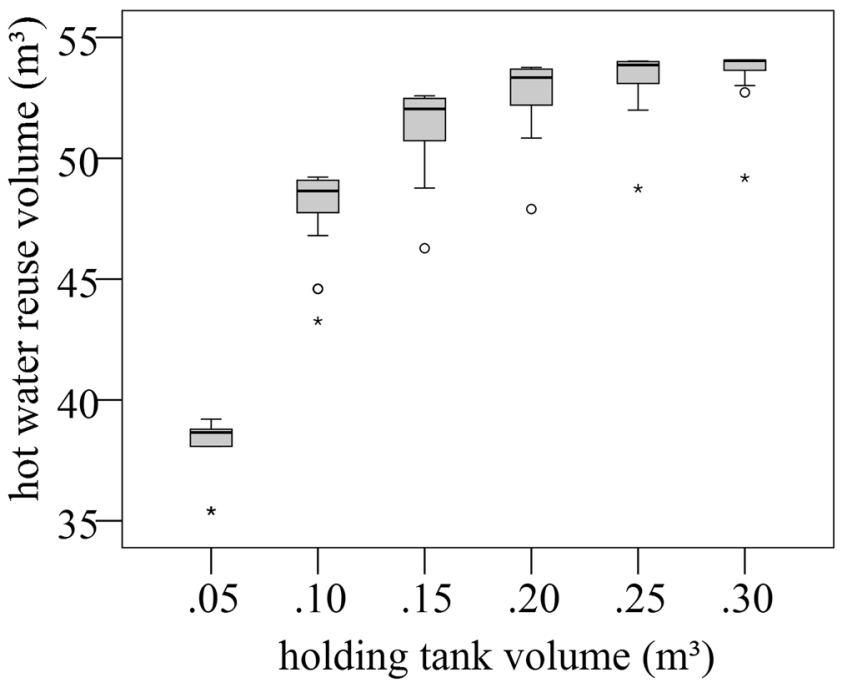

Fig. 6 Box-plots of the simulation output for scenario 2; impact of collection tank volume (upper left), holding tank volume (upper right) and treatment capcity (lower left) 
normality requirement for ANOVA analysis, but claim that the method is robust enough to yield meaningful results.

\section{Results and discussion}

\section{Baseline data}

The total water consumption during the period simulated (September 1st to November 1st, 2019) was measured to $204.726 \mathrm{~m}^{3}$ (132.916 and $71.846 \mathrm{~m}^{3}$ cold and hot water respectively), equaling $104.9 \mathrm{~L}$ per person and day. The distribution between utilities was 30.4, 21.5, 12.4, 10.6 and $25.0 \%$ for shower, toilet, bathroom sink, washing machines, and kitchen tap water respectively. The bathroom sink and shower represent 63.6 and $29.0 \%$ of the total hot and cold water consumption respectively during the period, as can be seen illustrated on Fig. 4.

The toilet flushing represents $33.1 \%$ of the total coldwater consumption, and the bathroom sink greywater could theoretically cover $57.8 \%$ of this need, if water was collected from all sinks. However, sinks in some public and utility spaces were excluded from collection in the simulation, and therefore the practical maximum could be considered to be somewhat lower.

\section{General observations}

In scenario 1, collection of bathroom sink greywater and recycling for toilet flushing resulted in an average of $19.99 \pm 0.52 \mathrm{~m}^{3}$ (for all parametric variations) recycled water, corresponding to $16.8 \pm 0.4 \%$ of the total cold-water consumption during the simulation period. This can be compared with scenario 2, where greywater was collected and reused in bathroom sink and shower. The recycled water volume was $49.50 \pm 5.67 \mathrm{~m}^{3}$, corresponding to $58.2 \pm 6.6 \%$ of the total hot water consumption, representing a reduction in electricity consumption for re-heating recycled water of $1.85 \pm 0.21 \mathrm{MWh}$.

It is worth noting that there is a reduction in cold water demand due to the lower hot water feed temperature as
Fig. 7 Box-plots of the simulation output for scenario 3. Hot water reuse volume is shown in the left column and cold water reuse volume in the right column. The impact from collection tank volume, holding tank volume, recycle threshold ratio and treatment capcity are show in rows $1,2,3$ and 4 respectively

discussed above, and thus the volume cold water that need to be mixed-in decreases, in this case by $5.8 \pm 0.7 \%$.

Scenario 3 was identical to scenario 2 with the addition of water being reused also for toilet flushing. The recycled hot and water was $47.29 \pm 5.28$ and $33.34 \pm 5.79 \mathrm{~m}^{3}$ respectively. This represent reductions of $55.6 \pm 6.1 \%$ and $30.6 \pm 3.9 \%$ of the main hot and cold-water consumption. The respective energy saved in scenario 3 was calculated to $1.71 \pm 0.20$ MWh (Table 6).

\section{Detailed discussion scenario 1}

In this simulation scenario, water was collected from bathroom sinks and reused for toilet flushing. The collection tank volume was the most significant factor for total recycled volume cold water $(p=0.00)$. From a system design point of view, it is important that the collection tank volume is sufficiently large to facilitate recycling, and for the studied building this volume would be approximately $0.1 \mathrm{~m}^{3}$. The recycled volume for the $0.02 \mathrm{~m}^{3}$ tank was $21.726 \mathrm{~m}^{3}(49.4 \%$ of the toilet flush demand) and for the $0.1 \mathrm{~m}^{3}$ tank it was $22.788 \mathrm{~m}^{3}$ (51.8\% of toilet flush demand and $89.6 \%$ of the theoretical maximum recovery).

Compared to previous published results, the present findings exceed the reported 28.7-34.8\% savings (Ghisi and Ferreira 2007), but fall short of estimates between 74 and $100 \%$ reported in another work (Leong et al. 2019), which is probably due to difference in the use patterns and measurement methodology.

The other investigated factors are clearly significant for the simulation output ( $p=0.00$ for both holding tank volume and treatment capacity), but their impact on the output were much smaller (see Fig. 5). The impact of collection tank volume is attributed to the irregular volumes being collected from the sinks, while the demand side
Table 8 Summary of the Anova analysis of the factor impact on simulation output variation for recycled hot water volume in scenario 2

\begin{tabular}{llrlrc}
\hline & SS & \multicolumn{1}{l}{$d f$} & MS & \multicolumn{1}{c}{$F$} & $p$ value \\
\hline A (collection tank volume) & 0.005 & 5 & $9.0 \times 10^{-4}$ & 96.4 & $1.2 \times 10^{-36}$ \\
B (holding tank volume) & 0.735 & 5 & 0.147 & $15,706.5$ & $4.6 \times 10^{-143}$ \\
C (treatment capacity) & 0.035 & 4 & 0.009 & 932.4 & $3.5 \times 10^{-78}$ \\
$\mathrm{~A} \times \mathrm{B}$ & 0.001 & 25 & $4.48 \times 10^{-05}$ & 4.8 & $8.9 \times 10^{-09}$ \\
$\mathrm{~A} \times \mathrm{C}$ & 0.002 & 20 & $8.03 \times 10^{-05}$ & 8.6 & $4.6 \times 10^{-14}$ \\
$\mathrm{~B} \times \mathrm{C}$ & 0.004 & 20 & $1.8 \times 10^{-4}$ & 19.3 & $7.9 \times 10^{-26}$ \\
Within & 0.001 & 100 & $9.4 \times 10^{-6}$ & & \\
Total & 0.782 & 179 & $4.4 \times 10^{-3}$ & & \\
\hline
\end{tabular}



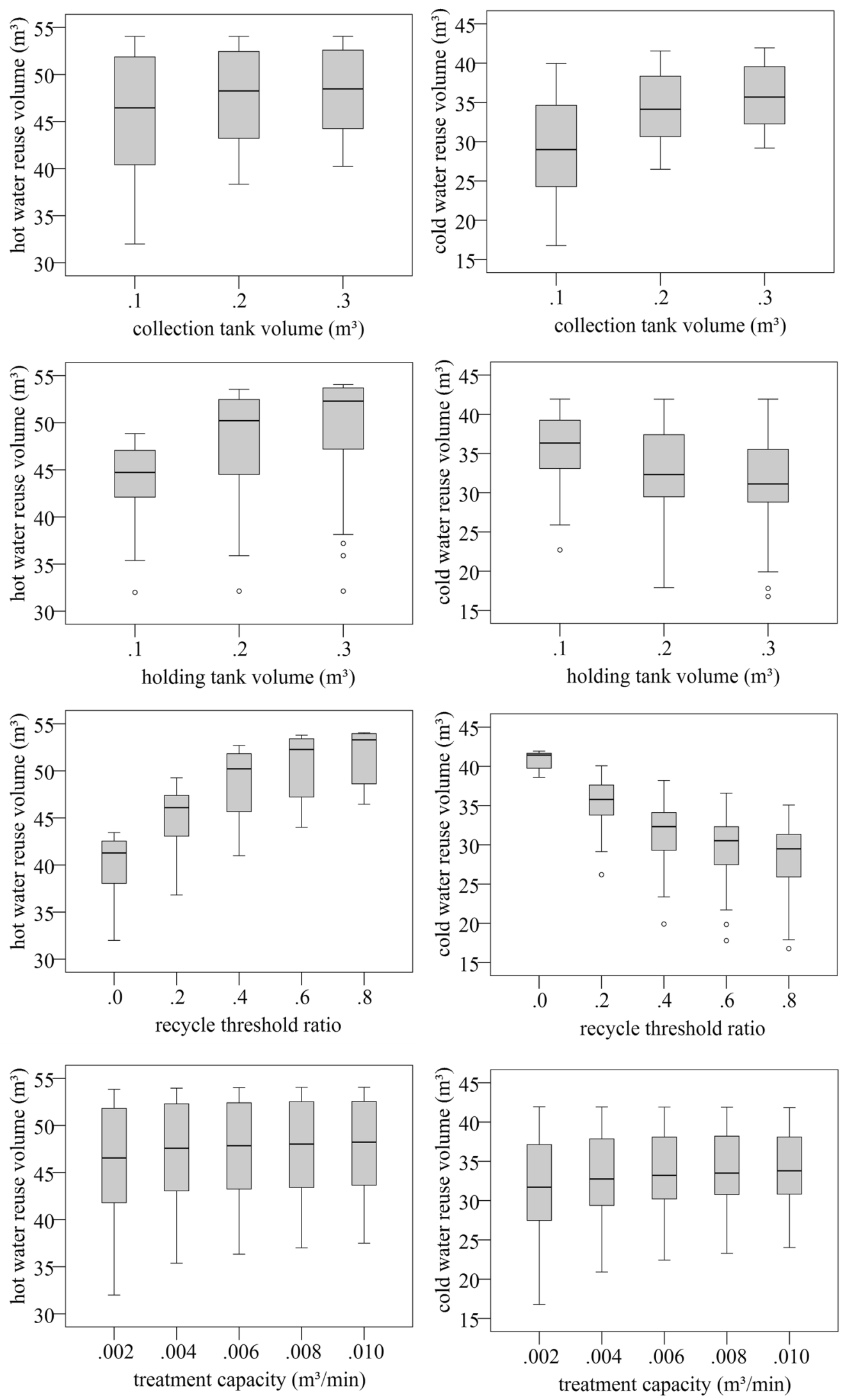
Table 9 Summary of the Anova analysis of the factor impact on simulation output variation for recycled hot water volume in scenario 3

\begin{tabular}{lrrrrr}
\hline & SS & $d f$ & MS & $F$ & $p$ value \\
\hline $\begin{array}{l}\text { A (collection tank } \\
\quad \text { volume) }\end{array}$ & 354.96 & 2 & 177.48 & 165.8 & $1.5 \times 10^{-41}$ \\
B (holding tank & 1640.26 & 2 & 820.13 & 766.2 & $8.9 \times 10^{-89}$ \\
$\quad$ volume) & & & & & \\
C (recycle threshold) & 4336.24 & 4 & 1084.06 & 1012.8 & $3.4 \times 10^{-122}$ \\
A $\times$ B & 5.82 & 4 & 1.45 & 1.360 .250 \\
A $\times$ C & 219.78 & 8 & 27.47 & 25.7 & $3.6 \times 10^{-26}$ \\
B $\times$ C & 275.64 & 8 & 34.46 & $32.195 .2 \times 10^{-31}$ \\
A $\times$ B $\times$ C & 7.11 & 16 & 0.44 & 0.42 & 0.977 \\
Within & 192.66 & 180 & 1.07 & & \\
Total & 7032.48 & 224 & 31.39 & & \\
\hline
\end{tabular}

is more regular, with $5 \mathrm{dm}^{3}$ toilet flushes, which rarely deplete the holding tank, even at the smallest volumes.

Based on the simulation output the most suitable scenario to apply as a hydraulic design guideline is to allocate $3 \mathrm{~L}$ of collection tank volume per connected user. A treatment capacity of $0.1 \mathrm{~L} \mathrm{~min}^{-1}$ per three connected users is sufficient for this scenario, as is a holding tank volume of $0.7 \mathrm{~L}$ per connected user. According to the modelling data, larger treatment capacities and holding tank volumes could not offer significant performance improvements.

Overall system performance variance in the outcome results was rather small with $2.3 \%$ RSD over all 150 simulation runs (Table 7).

\section{Detailed discussion scenario 2}

In scenario 2 where greywater was collected from and recycled as hot water to sink and shower, the holding tank volume had the most significant impact on recycled volume $(p<<0.01)$. The largest recycled volume for the $0.05 \mathrm{~m}^{3}$ tank was $36.732 \mathrm{~m}^{3}$ (79.5\% of the baseline shower and sink hot water demand) and for the $0.1 \mathrm{~m}^{3}$ tank it was $53.334 \mathrm{~m}^{3}$, corresponding to $115.4 \%$ of the baseline shower and sink hot water demand. The recycled volume is higher than the base line demand in the latter case because of the assumption that the hot water demand will be greater due to its lower feed temperature as discussed above.
Kruskal-Wallis test for independent samples showed that the treatment capacity also had a significant impact (predictor importance $0.04, p<<0.01$ ) on recovery and at $1 \mathrm{~L}$ per minute flow the system could not fully keep up with the demand. However, pairwise comparison showed that for treatment capacities over $2 \mathrm{~L}$ per minute there were no statistically significant difference (at 0.05 significance level) in the output.

Introducing larger than $0.1 \mathrm{~m}^{3}$ collection tank volume and higher than $0.002 \mathrm{~m}^{3} \mathrm{~min}^{-1}$ treatment capacity, however, had very little effect on the total recycled volume of hot water. Also, a larger holding tank than $0.25 \mathrm{~m}^{3}$ did not yield any significant performance improvement of the system (see Fig. 6).

There were significant two-way interaction effects on the output variance, meaning that the impact of collection or holding tank volumes depend on the volume of the other tank, and impact of both tank volumes depend on the treatment capacity, i.e. a very low capacity make the system design more sensitive to tank size selection in terms of hot water reuse efficiency (Table 8).

\section{Detailed discussion scenario 3}

In this scenario toilet flushing compete with sink and shower and the distribution principle becomes the determining factor. To promote recycling of treated water as hot water, which is the most favorable way from the energy conservation point, setting a high toilet flushing recycle threshold was the most significant factor $(p<<0.01)$ followed by holding the tank volume constant $(p<<0.01)$. Treatment capacity had limited impact on reuse volumes for the investigated factor levels, with a $5.4 \%$ difference in the total reused volume between 0.002 and $0.010 \mathrm{~m}^{3} \mathrm{~min}^{-1}$ which was also the best performing configuration. The decrease in holding tank capacity in the case of volumes of 0.1 and $0.3 \mathrm{~m}^{3}$ was only $1.1 \%$ total reused volume, but at the expense of higher treatment capacity need $\left(0.01 \mathrm{~m}^{3} \mathrm{~min}^{-1}\right)$ and a $9.6 \%$ worse performance for hot water reuse (see Fig. 7).

The obtained results showed that the impact of tank volumes does not significantly depend on each other $(p=0.25)$, but the impact of both tank volumes on the amount of reused hot water were each significantly dependent on the toilet reuse threshold ratio ( $p<<0.01$ in both cases). The toilet reuse threshold ratio can be used to control the preference
Table 10 Hydraulic design recommendations for the scenarios examined in this paper

\begin{tabular}{llll}
\hline & $\begin{array}{l}\text { Collection tank } \\
\text { volume }\left(\mathrm{dm}^{3} \text { conn. }\right. \\
\text { user })\end{array}$ & $\begin{array}{l}\text { Treatment capacity } \\
\left(\mathrm{dm}^{3} \min ^{-1} \text { conn. }\right. \\
\left.\mathrm{user}^{-1}\right)\end{array}$ & $\begin{array}{l}\text { Holding tank } \\
\text { volume }\left(\mathrm{dm}^{3} \text { conn. }\right. \\
\left.\text { user }^{-1}\right)\end{array}$ \\
\hline $\begin{array}{l}\text { Sink collection toilet reuse } \\
\text { Sink, shower collection and reuse }\end{array}$ & 3 & 0.033 & 0.7 \\
$\begin{array}{l}\text { Sink, shower collection and reuse } \\
\text { and toilet reuse }\end{array}$ & 3 & 0.067 & 8 \\
\hline
\end{tabular}


between reuse hot and cold water; setting a lower threshold ratio will result in preference for cold water/toilet flushing reuse. Typically, a high threshold ratio would be preferable from an energy conservation perspective.

Based on the obtained data from the simulations, the proposed design guidelines are; collection tank: $3 \mathrm{~L}$ per connected user, treatment capacity: $0.1 \mathrm{~L} \mathrm{~min}^{-1}$ per connected user and holding tank $10 \mathrm{~L}$ per connected user. It should be noted that it is possible to further decrease the treatment capacity to $0.033 \mathrm{~L} \mathrm{~min}^{-1}$ per connected user with only $2.5 \%$ decrease in recycled cold water (Table 9).

\section{Conclusions}

In the present work, in-building greywater recycling was simulated using highly disaggregated authentic data on water consumption of the users as input. As a result of the performed simulations the following main findings could be summarized:

- Mains cold water reduction of $16.7 \pm 0.4 \%$ was demonstrated by reusing bathroom sink water for toilet flushing, satisfying a maximum of $51.8 \%$ of toilet demand (scenario 1).

- Mains hot water reduction of $58.2 \pm 6.6 \%$ with the incidental reduction of mains cold water use by $5.8 \pm 0.7 \%$ was demonstrated by reusing bathroom sink and shower water for bathroom sink and shower, satisfying a maximum of $118.2 \%$ of the baseline hot water and $61.6 \%$ of sink and shower total water demand (scenario 2).

- Mains hot water reduction of $55.6 \pm 6.1 \%$ with the additional reduction of mains cold water use by $30.6 \pm 3.9 \%$ was demonstrated by reusing bathroom sink and shower water for bathroom sink and shower and toilet flushing, satisfying a maximum of $118.2 \%$ of the baseline hot water and $70.0 \%$ of toilet flushing water demand (scenario 3$)$.

Furthermore, hydraulic design recommendations for greywater reclamation systems that operate two tanks are proposed, as shown in Table 10. However, for environments where consumption patterns differ from what is presented here, operators may see other performance results.

In hot water reuse scenarios 2 and 3, energy expenditure for hot water production was reduced by between 1.72 and $1.85 \mathrm{MWh}$, corresponding to a reduction of between 43.5 and $46.8 \%$.

In the present study the potential of greywater reclamation on mains water consumption and energy expenditure was demonstrated through simulations. Future studies could be enriched with the inclusion of more micro consumption points, i.e. washing machines, as well as consideration of rainwater harvesting to complete the analysis of greywater reclamation potential.

Acknowledgements The authors wish to thank all who assisted in conducting this work.

Funding Open access funding provided by Chalmers University of Technology.

Open Access This article is licensed under a Creative Commons Attribution 4.0 International License, which permits use, sharing, adaptation, distribution and reproduction in any medium or format, as long as you give appropriate credit to the original author(s) and the source, provide a link to the Creative Commons licence, and indicate if changes were made. The images or other third party material in this article are included in the article's Creative Commons licence, unless indicated otherwise in a credit line to the material. If material is not included in the article's Creative Commons licence and your intended use is not permitted by statutory regulation or exceeds the permitted use, you will need to obtain permission directly from the copyright holder. To view a copy of this licence, visit http://creativecommons.org/licenses/by/4.0/.

\section{References}

Al-Jayyousi, O. R. (2003). Greywater reuse: towards sustainable water management. Desalination, 156(1), 181-192. https://doi. org/10.1016/S0011-9164(03)00340-0

Boretti, A., \& Rosa, L. (2019). Reassessing the projections of the World Water Development Report. NPJ Clean Water, 2(1), 15. https://doi.org/10.1038/s41545-019-0039-9

Bradley, R. M. (2004). Forecasting domestic water use in rapidly urbanizing areas in Asia. Journal of Environmental Engineering, 130(4), 465-471. https://doi.org/10.1061/ (ASCE)0733-9372(2004)130:4(465)

Butler, D. (1991). A small-scale study of wastewater discharges from domestic appliances. Water and Environment Journal, 5(2), 178184. https://doi.org/10.1111/j.1747-6593.1991.tb00605.x

Campisano, A., \& Modica, C. (2010). Experimental investigation on water saving by the reuse of washbasin grey water for toilet flushing. Urban Water Journal, 7(1), 17-24. https://doi. org/10.1080/15730621003596739

Campisano, A., \& Modica, C. (2014). Selecting time scale resolution to evaluate water saving and retention potential of rainwater harvesting tanks. Procedia Engineering, 70, 218-227. https://doi. org/10.1016/j.proeng.2014.02.025

Dixon, A., Butler, D., \& Fewkes, A. (1999). Water saving potential of domestic water reuse systems using greywater and rainwater in combination. Water science and technology, 39(5), 25-32.

European, P. (2018). Regulation of the european parliament and of the council on minimum requirements for water reuse. In E. parliament (Ed.), 2018/0169.

Ghisi, E., \& Ferreira, D. F. (2007). Potential for potable water savings by using rainwater and greywater in a multi-storey residential building in southern Brazil. Building and Environment, 42(7), 2512-2522.

Knutsson, J. (2019). jespknut/greywater-recycling. https://github.com/ jespknut/greywater-recycling.

Knutsson, J., \& Marx, C. (2016). The Habitation Lab as a platform for sustainable innovations in the built environment: a case study. 
Paper presented at the 16th International Multidisciplinary Scientific GeoConference, Albena, Bulgaria, June 28-July 6.

Leong, J. Y. C., Balan, P., Chong, M. N., \& Poh, P. E. (2019). Lifecycle assessment and life-cycle cost analysis of decentralised rainwater harvesting, greywater recycling and hybrid rainwater-greywater systems. Journal of Cleaner Production, 229, 1211-1224. https://doi.org/10.1016/j.jclepro.2019.05.046

Lopez Zavala, M., Funamizu, N., \& Takakuwa, T. (2002). Onsite wastewater differential treatment system: modeling approach. Water Science and Technology, 46(6-7), 317-324.

Mandal, D., Labhasetwar, P., Dhone, S., Dubey, A. S., Shinde, G., \& Wate, S. (2011). Water conservation due to greywater treatment and reuse in urban setting with specific context to developing countries. Resources, Conservation and Recycling, 55(3), 356361. https://doi.org/10.1016/j.resconrec.2010.11.001

Mekonnen, M. M., \& Hoekstra, A. Y. (2016). Four billion people facing severe water scarcity. Science Advances, 2(2), e1500323. https ://doi.org/10.1126/sciadv.1500323
Oron, G., Adel, M., Agmon, V., Friedler, E., Halperin, R., Leshem, E., et al. (2014). Greywater use in Israel and worldwide: Standards and prospects. Water research, 58, 92-101. https://doi. org/10.1016/j.watres.2014.03.032

Villarreal, E. L., \& Dixon, A. (2005). Analysis of a rainwater collection system for domestic water supply in Ringdansen, Norrköping, Sweden. Building and Environment, 40(9), 1174-1184. https:// doi.org/10.1016/j.buildenv.2004.10.018

Wada, Y., Flörke, M., Hanasaki, N., Eisner, S., Fischer, G., Tramberend, S., et al. (2016). Modeling global water use for the 21st century: Water Futures and Solutions (WFaS) initiative and its approaches. Geoscientific Model Development, 9, 175-222.

WWAP (2019). The United Nations world water development report 2019: leaving no one behind: United Nations Education, Scientific and Cultural Organization.

Zhang, D., Gersberg, R. M., Wilhelm, C., \& Voigt, M. (2009). Decentralized water management: rainwater harvesting and greywater reuse in an urban area of Beijing China. Urban Water Journal, 6(5), 375-385. 